Article

\title{
Promoting Sustainable Creativity: An Empirical Study on the Application of Mind Mapping Tools in Graphic Design Education
}

\author{
Yenan Dong *, Shangshang Zhu and Wenjie Li
}

\section{check for}

updates

Citation: Dong, Y.; Zhu, S.; Li, W. Promoting Sustainable Creativity: An Empirical Study on the Application of Mind Mapping Tools in Graphic Design Education. Sustainability 2021, 13, 5373. https://doi.org/10.3390/ su13105373

Academic Editors: Despo Ktoridou, Epaminondas Epaminonda,

Leonidas Efthymiou and Barbara Motyl

Received: 23 March 2021

Accepted: 7 May 2021

Published: 11 May 2021

Publisher's Note: MDPI stays neutral with regard to jurisdictional claims in published maps and institutional affiliations.

Copyright: (c) 2021 by the authors. Licensee MDPI, Basel, Switzerland. This article is an open access article distributed under the terms and conditions of the Creative Commons Attribution (CC BY) license (https:// creativecommons.org/licenses/by/ $4.0 /)$.
School of Design and Architecture, Zhejiang University of Technology, Hangzhou 310023, China; zhuss21@zjut.edu.cn (S.Z.); jawenli@zjut.edu.cn (W.L.)

* Correspondence: dongyenan@zjut.edu.cn

\begin{abstract}
The development of creative thinking and creative problem solving is an important part of modern sustainable education. In teaching graphic design, educators should ensure the cultivation of sustainable creativity among students. Creative thinking and program development can be facilitated with the help of effective thinking tools. Among the various thinking tools, mind maps represent an easy-to-use visual diagram-based divergent thinking tool. However, few studies have examined the impact of mind maps on sustainable creativity in the design discipline. Similarly, few empirical studies have been conducted to analyse deeply the functional structure of and a graphic design education based on mind mapping. This study aims to examine the relation between students' use of mind mapping tools and sustainable creativity in implementing mind mapping-based graphic design activities with a sample size of 35 first-year design students. Through an empirical experiment, each student was asked to create a mind map and generate a new graphic design work based on the given experimental materials. The results showed that the mind mapping tool plays an important role in the pre-conceptualization phase of the design process. This tool can effectively help designers develop creative ideas, stimulate their minds, and help them maintain their creative energy and have a sustainable and innovative creative ability.
\end{abstract}

Keywords: creativity; sustainability; creative thinking; mind mapping tool; graphic design education

\section{Introduction}

Creativity is typically defined as the ability to produce novel and useful products in a given social context [1]. It is a topic of wide scope that is important at both the societal and individual levels for a wide range of task domains [2]. At a societal level, organizational creativity was defined as the creation of a valuable, useful new product, service, idea, procedure, or process by individuals working together in a complex social system [3]. Innovation is one of the motivators of the sustainable development of organizations [4]. At an individual level, creativity is used to solve problems [2], and it is a function of three components: expertise, creative thinking skills, and motivation [5]. The concept of creativity in this study refers to individual creativity. Therefore, training a large number of outstanding, quick-thinking, and well-educated creative talents, while leading their creative abilities towards sustainable development, has become a social and economic strategy among countries to solve their sustainable development problems. Expanding innovation education into sustainable innovation education and strengthening the cultivation of college students' innovation ability can promote the future development of college students and meet the requirements of a national sustainable development strategy. Higher-education students are at the age where their minds and imagination are at their richest and most creative. As such, integrating the concept of sustainable development into higher education will cultivate a group of modern and talented individuals. 
Sustainable creativity can be understood as the sustainability of the creative process, which concerns sustainability not as a means but as an end in itself [6]. Creativity and innovation have long been recognized as critical to ensuring sustainable competitive advantages, added value, and even survival [7]; they are higher-order psychological functions that distinguish humans from other animals [8]. Creativity plays a central role in sustainable development [9] and is an important tool in searching for a more sustainable future [10]. 'Sustainable development' aims to improve sustainability among people's creativity, which will help humankind fully adapt and transform their living environment and maintain it with sustainable development. Sustainable innovation capability is aligned with society's sustainable development strategy; it is the ability to innovate continuously. Innovation is the most important source of power for a country's economic development. The term 'sustainable learning' refers to education and teaching that can achieve a sustainable lifestyle. It is the transferability of learning from formal environment to informal environment, or it can also be called lifelong learning. The ability of sustainable learning and creativity needs to be developed in graphic design education [11]. This study focuses on how to cultivate students' sustainable creativity in graphic design teaching and practice activities.

Graphic design is one of the most important foundational disciplines for cultivating the creative potential of design students. It can develop students' thinking abilities and imagination, as well as help them think creatively, learn to accumulate design knowledge from real life, and discover new design elements. Graphic design is an ideal discipline for practicing and developing creative problem solving. An integral part of the graphic design process is sustainable creativity, which is an inexhaustible driving force for innovation. A modern approach to design that promotes creativity should emphasize the importance of critical thinking skills, technical skills, positive attitudes, and other relevant values [12]. In teaching and conducting graphic design activities, an especially important aspect to focus on is the cultivation of students' sustainable creativity, which entails helping students develop a more sustainable way of learning. The essence of graphic design education is improving the creative thinking ability of new design students [13]. Creative thinking helps designers find design solutions for new products or improvements for established products. It is also an important component of sustainable innovation design [14,15]. One of the core responsibilities of design teachers is to develop the critical thinking process of novice designers [16]. Divergent and inspirational thinking, when included in the teaching of creative design thinking, can help students develop creative thinking skills and promote sustainable innovation among designers. Currently, many educational institutions are placing increasing emphasis on the concept of creativity: 'Creativity is now as important as literacy in education, and should be treated with the same status'. Creativity develops students' ability to express themselves and use their imagination to solve problems by creating novel and valuable solutions [17]. Indeed, design students can develop their sense of aesthetics and creative expression through early graphic design training, thereby improving their visual communication skills and design aesthetics, and laying the foundation for later design practices (e.g., product design, architecture, and interactive design) [18-21] Graphic design is a creative field that requires students to think outside the box [22]. In the field of graphic design, creativity refers to a student's ability to solve various problems consistently. Problems in design are often seen as creative problems [23]. Therefore, problem-solving includes finding appropriate solutions. The goal of graphic design education is to guide students' intuitive and conscious efforts in creating a meaningful order out of design-related elements [24]. A challenge faced by every graphic design educator is carrying out teaching activities while also contributing towards the development of sustainable innovation abilities among their students.

Thinking tools help students to learn, think, and express in a visualized way, so as to help students broaden their thinking space and cultivate higher-order thinking ability. The use of thinking tools in graphic design education contributes to creative thinking and program development. Thinking tools also help innovative individuals maintain their creative energy. Kokotovich's [16] creative mental synthesis experiment showed that 
when subjects are asked to develop ideas without concretizing concepts mentally, they are able to produce a greater number of creative ideas. Therefore, introducing industrial designers to problem-structuring strategies and tools has proven beneficial in bringing their design thinking framework closer to that of design professionals. Divergent thinking is the natural thinking mode of human brain. Divergent thinking tools can adapt to the needs of brain thinking mode. They can frame various trivial text content into a hierarchical tool map with symbols and lines, images, and vocabulary, which has the positive effect of clearly and efficiently leading the process of divergent thinking. In the process of using divergent thinking, the relationship between individual ideas and ideas is constantly expanding, resulting in more new ideas and the emergence of original ideas. Graphic creativity always depends on the creative association of designers. The association method can help designers to open the channel of creative thinking, make the invisible ideas transform into tangible images, and create new images [25]. Oxman believed that mind maps represent a simple and easy-to-use thinking tool based on visual diagrams that are also teachable [26]. It can effectively help designers make creative associations and stimulate their minds. The use of innovative design technology can maximize the potential of creative thinking, helping designers design novel and advanced products that meet people's needs. Designers are recommended to use proper divergent thinking methods (e.g., mind maps) to organize relevant thoughts and produce innovations in product design quickly [27]. Many researchers found that mind mapping was a useful tool and a kind of widely recommended creativity technique to enhance idea generation [28-32]. Mind mapping can produce the highest level of fluency and originality in more complex tasks. They seem to release the full potential of mind mapping technology, thus making the best use of the increase in information density and the interconnection of more complex tasks [28]. Mind-maps help people activate and combine knowledge systematically and display underlying mental models in a clear perceptible way [33]. Therefore, we consider mind mapping as a preferred tool in the early stages of creative design conception.

Although some studies have shown that the use of mind mapping tools can effectively boost people's thinking and stimulate creativity, only a few theoretical studies have systematically analysed creative design from a noetic science perspective. The influence of mind mapping on sustainable creativity has not been clearly detailed, nor has there been sufficient exploration into its influence on teaching and learning graphic design. In-depth analyses of the functional structure of mind mapping remain scarce. Moreover, empirical research on graphic design education based on mind mapping does not follow a systematic methodology. The present study focused on the broad role of mind mapping in the graphic design process and its succeeding design outputs. We aimed to address the following questions: (1) What is the relation between students' use of mind mapping tools and sustainable creativity in implementing mind mapping-based graphic design activities? (2) What forms of mind mapping perform better in promoting sustainable creativity? To this end, this study carried out a theoretical and practical exploration of teaching mind mapping-based graphic design. The next section presents a review of related literature that has attempted to shed light on the graphic design process and the influence of mind mapping tool use on sustainable creativity.

\section{Literature Review}

\subsection{Graphic Design Process}

Graphic design refers to the harmonious combination of various basic graphical elements with those that have explanatory functions (e.g., fonts, text, colours, graphics, and photos). It also aims to create visual expressions imbued with the designer's imagination and unique organizational method to convey information, communicate emotions [34-37], and provide profound moral and ideological connotations to images. Graphic designers find the most suitable solution through a series of creative processes [17]. Designers try to express or explain matters in a graphical language, which can be verbal, pictorial, or schematic, and present them either on paper or digital screens [38]. The scope of graphic 
design work and education continues to expand; graphic designers have worked in many fields, such as communication, media, and branding [39]. In short, graphic designers play an important role as 'message and image shapers' during the process of transforming ideas and concepts into visual design solutions [40-43].

Studying the creative process can shed light on the function of the designer and on proper teaching methods. The entire creative and critical thinking process involves transforming abstract concepts into concrete visual images. In the conception process, it is important to have a clear understanding of the end goal to be reached via graphical images, to grasp the theme, to position the work correctly, to have an open mind with the help of various forms of thinking, and to visualize abstract concepts in a stepwise manner. Connections to other ideas are usually determined after evaluating and gathering evidence of all possible links [44]. The creative process of graphic design usually involves going through a series of processes, such as thematic analysis, definition of the topic, research, conceptualization, selection, verification, and production. Currently, many scholars and organizations are working to understand the design process, and research has been conducted on developing diverse design process models to increase creativity. These models, often referred to as 'innovation process' models [17,45-47], can be summarized as having two phases:

1. Analysis phase (assimilation and general study): In this phase, the designer clarifies the topic and proceeds with an initial processing of currently available information to understand it better [17]. Analysis of and research into the graphic design theme are carried out, along with further research and categorization of the topic's various characteristics. Once done, both are combined. After the themes are sorted and broken down, the creative process is applied to the themes and their sub-themes. During this process, the brain needs to work fast, mobilize all its brain cells for creativity, and constantly think outside the box. However, in the conceptualization process, it is necessary to refer to the original theme and then think outside the box, constantly repeating this thinking cycle.

2. Design phase (development and communication): The designer begins designing and developing creative ideas from the first phase. They fully understand and extract visual symbols. Designers analyse, synthesize, and summarize all kinds of information around their new ideas and then seek the perfect solution through convergent thinking. Simply put, the creative process generally develops ideas from a 'schematic diagram' into a 'sketch'; it is a process of collecting, classifying, organizing, analysing, and researching materials, and then further developing ideas towards completion. Through the stimulation of creative inspiration; proper usage of basic modelling language and artistic mediums (e.g., point, line, and surface); design process of selecting, analysing, combining, breaking down, and reconstructing graphics; careful planning; and use of visual elements (e.g., colour, shape, and substance), viewers are shown the newly organized artistic graphical expression of the designer's thoughts.

\subsection{Role of Mind-Mapping Tools in Promoting Sustainable Creativity}

Mind mapping is an innovative note-taking method proposed by British psychologist and educator Tony Buzan in the 1970s [16,48,49]. Mind mapping is defined as referring to the 'non-linear visual contours of complex information, which can help creativity, organization, productivity, and memory' [33,50]. It is a divergent thinking method that uses the brain effectively and stimulates the radial structure of the brain's neural network. It is known as a 'mind map', 'psyche map', or 'brain map' because it uses visual icons to represent the brain's cognitive structure. Mind maps are key to unlocking the brain's potential [51] and are designed to uncover creative connections between ideas or concepts [33]. Mind maps are diagrams used to express concepts, ideas, or tasks, helping students organize information and ideas and then solve problems [52-54]. Mind maps are graphical tools that unlock the brain's potential by managing ideas according to hierarchical categories 
and forming connections between them, thereby helping designers generate new thought structures with creative and organized ideas $[55,56]$.

Mind maps are a non-linear network-structured form of expressing ideas, and this organizational paradigm is based on radial thinking [54]. Mind maps use lines, colours, characters, numbers, symbols, and pictures to record information and ideas quickly [57]. The structure is open and organized, allowing one to organize a wide variety of information and generate new ideas. Any idea can be linked to another idea in mind maps. Free-form, spontaneous thinking is required when creating mind maps, with the goal of finding creative connections between ideas. The brain works by starting with a central focus and then working outwards in a random but organized fashion [48,58]. Mind maps are advantageous because they are 'free form' and have an 'unconstrained structure'. There are no restrictions on ideas or links, and there is no need to have an ideal structure or format. Mind maps are a tangible manifestation of stream-of-consciousness thinking, which constantly branches out, reconnects, and branches out again [59]. Mind maps allow people to focus on a single topic, help show the connection between isolated pieces of information, and provide a clear picture of small details and overview of all pieces of information [60]. Mind maps are considered a good starting point in showcasing the breadth and main components of research methodologies; this type of visual and non-traditional presentation style can be used to learn, understand, and teach research methodologies [61]. Mind mapping has a positive effect: it can boost the brain's potential and help people think outside the box to find ideas or solutions to problems. The visualization aspect of mind maps has the following advantages: first, it presents information in a structure that helps people grasp the overall information, understand key points, avoid getting lost in detail, and increase their information capacity. Second, its radial arrangement of keywords easily triggers associative and stimulative thinking. Mind maps use text, colours, pictures, and codes to map out thought processes from multiple perspectives; thus, a person's attention is focused on a central theme or image. It allows for a clear depiction of different modes of thinking, making it an effective tool for organizing and elaborating ideas, a source of inspiration and divergent thinking, and a way for people to think more creatively.

Mind mapping has been widely used in many fields, including Finance [62], Economics [63], Marketing [64], and Executive Education [65]. It is also widely used in professions such as Art and Design field. For example, Leeds et al. [66] emphasized the superiority of mind maps over associating ideas in a list format. Mind maps provide a more concise overview of the hierarchy of ideas and knowledge networks. This feature is especially important for designers and engineers who need to generate new ideas constantly. By providing a comprehensive map of ideas in a single visual layout, mind maps allow individuals to reduce their working memory load and see problems from a broader perspective. For example, in an educational context, students should not be discouraged by seemingly mundane starting ideas. Rather than requiring initial ideas to be good and shutting down bad initial ideas, teachers should help students explore their ideas indepth. Leeds et al. [66] also presented future studies on associative studies with new avenues of exploration by examining the various dimensions of mind maps. Thamrin [67] suggested that a mind map-based design approach is of great value to the interior design discipline. Regular usage of mind maps in conceptual design can help individuals develop a unique way of thinking, develop creative thinking skills, and enhance problem-solving skills [48,53,68-70]. Widiana and Jampel [71] recommended that teachers use a mind mapassisted multiple-intelligences approach, which is an innovative teaching model designed to improve students' creative thinking skills.

\section{Materials and Methods}

\subsection{Experimental Design}

Studies have shown that designers' probability of producing creative design solutions greatly increases when they are free to think outside the box and draw dynamic connections between design problems [16]. To verify this point, we introduced mind maps in the 
preconception phase of graphic design, with the goal of exploring how implementing mind maps can impact graphic design education and the sustainable creativity of novice design students, specifically evaluating thinking ability and creative output.

\subsubsection{Participants}

A total of 35 participants (ages 18 to 20 years, $63 \%$ of whom were women) participated in the experiment. They were first-year undergraduate students majoring in industrial design at Zhejiang University of Technology in China. They had already completed courses on Composition and Colour Theory and possessed basic knowledge in visual composition and colour matching. These participants were chosen because they could benefit from this study's experimental interventions and were unlikely to have extensive prior knowledge and experience. Prior to the experiment, the participants were not informed of the goal of the experiment. They had relatively similar design abilities as novices in the field of design.

\subsubsection{Experimental Materials}

Each participant in the experiment was given the same subject material: Wang Mian's painting entitled 'Pale-dark Plum Blossom' (Figure 1). Wang Mian is an ancient Chinese painter and poet, and 'Pale-dark Plum Blossom' is considered a masterpiece among his collection of artistic works. The painting is in a landscape orientation and features plum blossoms on branches. It has a pleasing composition, and the blossoms and branches are painted in simple and elegant strokes with the appropriate amount of ink and brush strokes, thereby accentuating the vibrant, clear, and spontaneous quality of plum blossoms while not overly complicating the scene. It is sparse amid dense subjects.

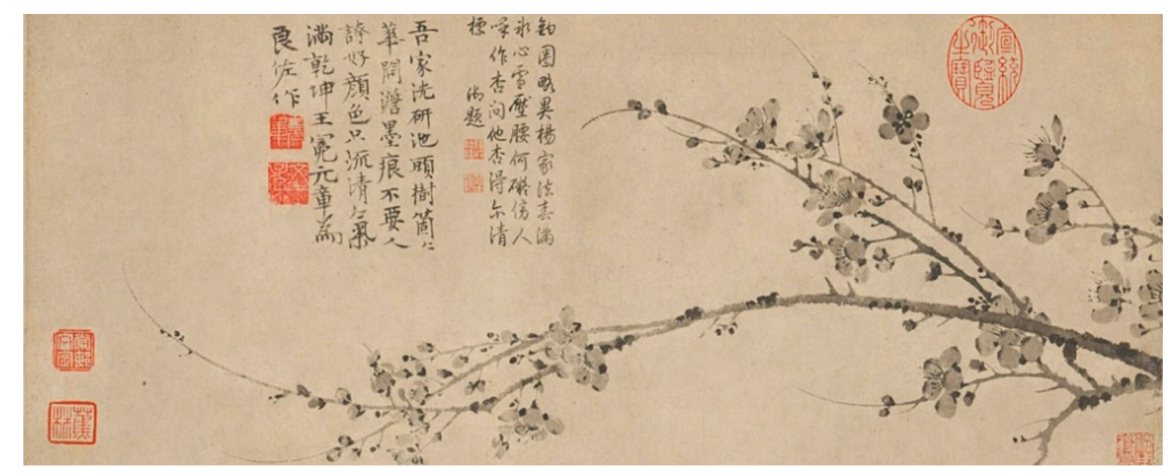

Figure 1. Wang Mian's painting entitled 'Pale-dark Plum Blossom'.

Wang Mian also wrote a poem on the painting that explains the work. This type of improvised poetry based on the painting's content is called a 'poem inscribed on the painting,' and it unifies the poem and painting into one work. The poem refers to how the plum trees by the small pond in the painting are in full bloom, and each plum blossom is dyed with light-coloured ink. Although the plum blossoms do not look tender and beautiful on the outside, they are delicately fragrant, elegant, and noble on the inside. The artist chose not to use bright colours to attract and please viewers or seek their praise; rather, his choice of colours helped the blossoms exude a delicate fragrance, apart and aloof from worldly affairs. The original text of the poem is as follows:

In the pond the brushes and inkstone I clean,

The trees above it all pale-dark blossoms bear.

For praises of fair colours, they appear not to care,

But leave to the vast universe their scents serene.

\subsubsection{Experimental Procedures}

All participants were invited into a closed-off classroom to avoid disturbing other students. The participants all worked individually and were not allowed to discuss 
with one another. The experimenters provided participants with drawing tools, such as pencils, brushes, gouache paint, and white paper. Each participant was asked to think about the given theme and then complete a $10 \mathrm{~cm} \times 10 \mathrm{~cm}$ graphic design piece within a specified time (180 $\mathrm{min}$ ). The first step in graphic design is understanding the content of the message to be conveyed; this is usually given to the designer in two parts: an original prototype and its meaning. The designer then organizes relevant elements together effectively and creatively to convey the message accurately. This is a common practice in the discipline. Doing so means the original prototype does not necessarily appear in the final product. Some researchers have established 'innovation process' models [17,45-47] with different procedures. It can be summarized as two phases: analysis phase and design phase. Therefore, the experiment in this study involved two experimental tasks: an analysis task and a design task. The experimental procedure is shown in Figure 2:

1. Provide participants with an introductory document on the entire experimental procedure. This step lasts for $10 \mathrm{~min}$.

2. Creating a mind map. Participants are asked to read carefully and appreciate the imagery and poem in Wang Mian's 'Pale-dark Plums', look for inspiration from the text and imagery, and use mind maps for creative association and idea development, with no limit to the mind map's form. This step lasts for $30 \mathrm{~min}$.

3. Executing creative designs. Participants are asked to execute a creative design based on their mind map from Task 1 and use the provided drawing tools to complete their final design. They are also instructed to write down descriptions about their design output. This step lasts for $140 \mathrm{~min}$.

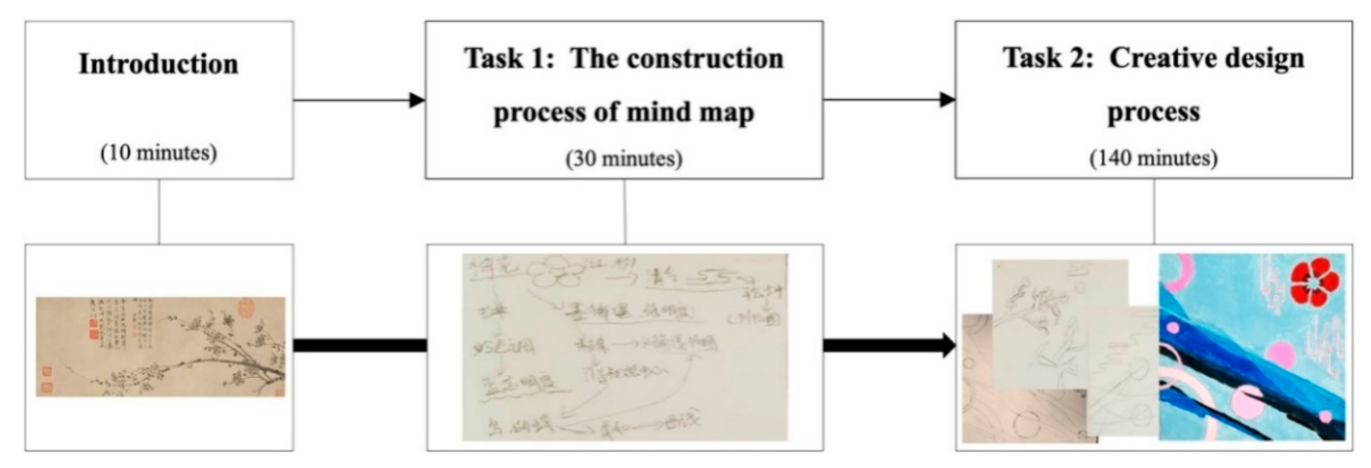

Figure 2. The experimental procedure.

\subsection{Evaluative Work}

We collected the participants' works from Tasks 1 and 2. The mind maps from Task 1 and creative outputs from Task 2 were then evaluated. The evaluation results for each stage are as follows.

\subsubsection{Evaluation Indicators for the Mind Map}

The mind map evaluation focused on how participants presented information visually, the connections they made between pieces of information, and their levels of thinking. The mind map itself, originally a visual expression of information and thought, can make a person's tacit knowledge visible. As such, the mind map becomes a visual representation of the thoughts in a human mind. Therefore, the mind map evaluation focused on both the results and the process. Evrekli et al. [72] developed a visual evaluation scale for mind maps, with the multiple relations between concepts and ideas constructed by individuals being the core of the evaluation. The present study categorized all knowledge and viewpoint connections into different complexity levels, with the scoring method shown in Table 1. 
Table 1. Scoring system.

\begin{tabular}{ccc}
\hline Item & Score & Example \\
\hline & 1st level: 2 point \\
2nd level: 4 point & 3rd level: 6 point \\
Concept links level: 8 point & 5th level: 10 point \\
& 6th level: 12 point \\
\hline Image & 3 point for each \\
\hline Relationships & 3 point for each
\end{tabular}

The students were encouraged to draw freely a mind map on a blank sheet of paper. After, the experimenters used mind mapping software to redraw their mind maps to score them better. Figure 3 shows the mind map drawn by Participant 5 in Task 1 . Figure $3 a$ is the hand-drawn version, whereas Figure $3 \mathrm{~b}$ is the digital version. Participant 5's mind map clearly demonstrated their analysis and association process of the main elements, as well as their construction method of a unique and creative organization map in shaping a comprehensive analysis of the central theme. The experimenters performed a statistical analysis based on three indicators: concept links, image, and relationships. According to the scoring criteria, the concept link indicator scored a total of 54 points based on thethree different mind map hierarchy levels, as shown in Figure 3, with the first level given 10 points, the second level, 32 points, and the third level, 12 points. Figure 3 shows the mind map as featuring three images. The image indicator scored a total of 9 points. The relationships indicator scored 0 point because there was no sign of any relations present in the mind map.

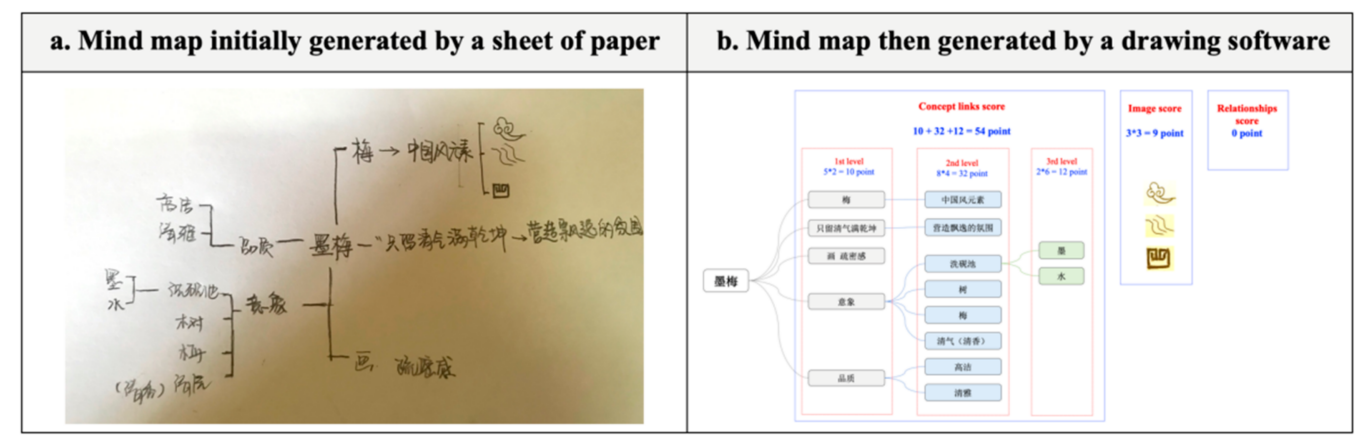

Figure 3. The mind map drawn by Participant 5 in Task 1.

\subsubsection{Evaluation Indicators for the Creative Output}

Amabile [73] noted the scarcity of objective methods for evaluating the creativity of products. Generally, evaluation is done through subjective judgments. Shalley and Gilson [74] supported Amabile's point and argued that only experts in the field can determine whether creative elements are present in a particular idea, or in other words, whether an output is creative or not. Therefore, we invited two experts to evaluate the 35 participants' graphic design output from Task 2. Both judges were experienced graphic designers with five or more years of professional experience. A clear definition of a creative design output that consists of measurable elements will allow researchers to measure the effectiveness of any new creative tool or method. Most scientific literature describes an output as creative when it is original and appropriate, per the criteria defined by existing literature on measuring creativity in different fields [37,45,75-77]. The sustainable creativity in the experiment can be defined as the creative process of intentionally reusing and updating old versions when developing meaningful and durable solutions, and was evaluatedwith two evaluation metrics (originality and appropriateness). Originality refers 
to the novelty of the solution relative to other solutions, while appropriateness refers to the feasibility, rationality, and development potential of the solution. In the assessment process, the experts first saw all the works before starting the evaluation, because in this case, the originality is decided comparing to group responses. Figure 4 shows the creative design output made by Participants 22 and 6 in Task 2.

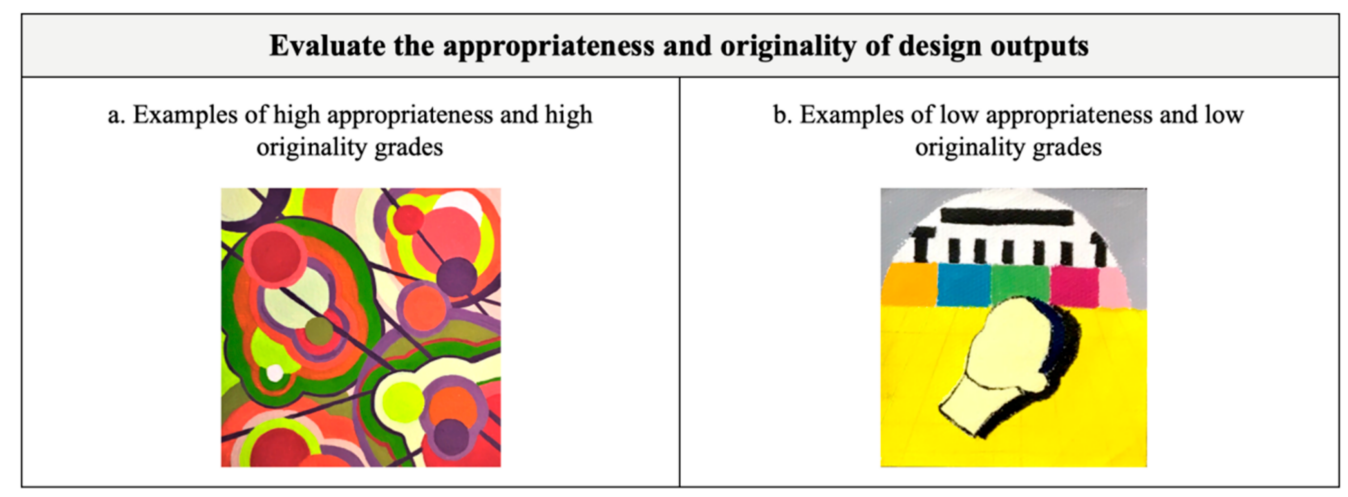

Figure 4. The creative design outputs made by Participant 22 (a) and Participant 6 (b) in Task 2.

\section{Results}

\subsection{Evaluation Results of the Mind Maps from Task 1}

As shown in Figure 5a, more than half of the participants (54.3\%) produced mind maps with three to fourhierarchy levels. Most of the mind maps made by the participants $(68.6 \%)$ contained relation diagrams or images, showing a non-hierarchical mind map pattern (Figure $5 b$ ).

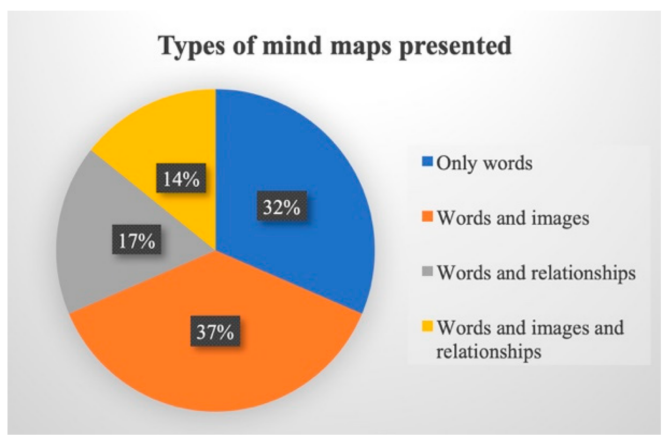

(a) Types of mind presented

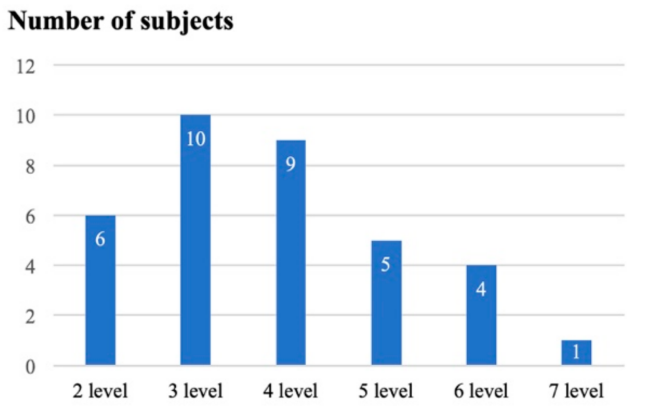

(b) Number of subjects

Figure 5. Statistic chart of mind mapping.

The experimenters categorized the 35 mind maps under the three indicators of concept links, image, and relationships, and then arranged them from 1 to 35 to analyse how each evaluation indicator correlated with the outputs from Task 2.

\subsection{Evaluation Results of the Design Output from Task 2}

Two experts evaluated the creativity of all 35 works from Task 2 . Studies have typically used Pearson's coefficient test to calculate inter-rater reliability $[47,77-79]$. We used the Pearson correlation coefficient to calculate the correlation of both judges' evaluations. The results revealed a significant correlation between the scores given by both evaluators, as shown in Table 2 (appropriateness: $p<0.05$; originality: $p<0.01$ ). 
Table 2. Inter-rater agreement between the two judges.

\begin{tabular}{ccc}
\hline Dependent Variable & Sig. (2-Tailed) & r (Judges 1 \& 2) \\
\hline Appropriateness & 0.039 & $\mathbf{0 . 3 5 1 *}$ \\
Originality & 0.009 & $\mathbf{0 . 4 3 2} * *$ \\
\hline
\end{tabular}

* Correlation is significant at the level of 0.05 . ${ }^{* *}$ Correlation is significant at the level of 0.01 .

In reference to the methodology used in literature [16], each expert evaluator ranked and scored the design output based on two criteria: appropriateness and originality. Figure 6 shows the scoring scale and the two methods of ranking/scoring the design output. For each evaluation criterion, the expert evaluator reviewed each student's design output and ranked it on a scale of 1 to 35. Additionally, they scored each output on a scale of 0 to 100 . The expert evaluators were asked not to have duplicate scores to ensure that the rankings would be clear. Finally, the scores given by both experts were averaged, which were subsequently ranked from highest to lowest.

\begin{tabular}{|c|c|c|}
\hline Rank & $\begin{array}{l}\text { Subject's code } \\
\text { number }\end{array}$ & $\begin{array}{l}\text { Rating of the } \\
\text { appropriateness (Score } \\
0-100)\end{array}$ \\
\hline \multicolumn{3}{|l|}{ Rank 1} \\
\hline \multicolumn{3}{|l|}{ Rank 2} \\
\hline \multicolumn{3}{|l|}{ Rank 3} \\
\hline \multicolumn{3}{|l|}{ Rank 4} \\
\hline & & \\
\hline & & \\
\hline & & \\
\hline$\nabla$ & $\nabla$ & $\nabla$ \\
\hline \multicolumn{3}{|l|}{ Rank 32} \\
\hline \multicolumn{3}{|l|}{ Rank 33} \\
\hline \multicolumn{3}{|l|}{ Rank 34} \\
\hline Rank 35 & & \\
\hline
\end{tabular}

\begin{tabular}{|c|c|c|}
\hline Rank & $\begin{array}{l}\text { Subject's code } \\
\text { number }\end{array}$ & $\begin{array}{l}\text { Rating of the originality } \\
\text { (Score 0-100) }\end{array}$ \\
\hline \multicolumn{3}{|l|}{ Rank 1} \\
\hline \multicolumn{3}{|l|}{ Rank 2} \\
\hline \multicolumn{3}{|l|}{ Rank 3} \\
\hline \multicolumn{3}{|l|}{ Rank 4} \\
\hline & & \\
\hline & & \\
\hline & & \\
\hline$\nabla$ & $\nabla$ & $\nabla$ \\
\hline \multicolumn{3}{|l|}{ Rank 32} \\
\hline \multicolumn{3}{|l|}{ Rank 33} \\
\hline \multicolumn{3}{|l|}{ Rank 34} \\
\hline Rank 35 & & \\
\hline
\end{tabular}

Figure 6. The scoring scale and the two methods of ranking/scoring the design output.

\subsection{Correlation between the Mind Maps from Task 1 and the Design Output from Task 2}

Kokotovich [16] suggested the use of ranked differences correlation to test the relation between the three evaluation indicators (concept links, image, and relationships) of the mind maps and the two evaluation indicators (appropriateness and originality) of the design output. To determine the degree of correlation between the different scoring methods, we used rank difference correlation, a recognized statistical method. We corrected the rank differences, which resulted in tied scores. Although the expert evaluators were asked not to give duplicate scores, tied scores could appear from the averaging of the scores. Therefore, we rectified the tied scores [16]. The experimental results showed that the participants' performances in the two tasks were correlated. The correlation analysis of score differences is as follows (Table 3):

(1) The appropriateness of the design output was partially correlated with the mind map's score. The design output's appropriateness had a weak positive correlation with the mind map's concept links score. The design output's appropriateness had a strong positive correlation with the mind map's image score. The design output's appropriateness did not correlate with the mind map's relationships score.

(2) The design output's originality was partially correlated with the mind map's score. The design output's originality did not correlate with the mind map's concept links score. The design output's originality had a strong positive correlation with the mind map's image score. The design output's originality did not correlate with the mind map's relationships score. 
Table 3. Correlation analysis using the rankings revealed the following results.

\begin{tabular}{|c|c|c|c|}
\hline & Concept Links & Image & Relationships \\
\hline Appropriateness & $\begin{array}{c}\mathbf{0 . 3 4 5} * \\
\text { Sig. }(2 \text {-tailed })=0.043\end{array}$ & $\begin{array}{c}\mathbf{0 . 4 0 6} \\
\text { Sig. } \\
(2 \text {-tailed })=0.015\end{array}$ & $\begin{array}{c}0.178 \\
\text { Sig. }(2 \text {-tailed })=0.306\end{array}$ \\
\hline Originality & $\begin{array}{c}0.296 \\
\text { Sig. }(2 \text {-tailed })=0.085\end{array}$ & $\begin{array}{c}\mathbf{0 . 4 4 3}{ }^{* *} \\
\text { Sig. }(2 \text {-tailed })=0.008\end{array}$ & $\begin{array}{c}0.256 \\
\text { Sig. }(2 \text {-tailed })=0.138\end{array}$ \\
\hline
\end{tabular}

${ }^{*}$ Correlation is significant at the level of $0.05 .{ }^{* *}$ Correlation is significant at the level of 0.01 .

\section{Discussion}

\subsection{Influence of Early Mind Map Usage on Succeeding Design Outputs}

The present study aimed to explore the impact of mind mapping tools on sustainable creativity during the graphic design process. The results showed that participants' performance in the two experimental tasks was correlated; participants' performance in creating mind maps in Task 1 tended to affect how creative their design output in Task 2 was.

In task 1 , the number of students who produced mind maps with both words and images ranks the highest, which is 37 percent. The results were in line with previous studies. According to Lin and Shih 36, the overall respondents obtained a higher utility from mind maps presented to them with both words and drawings. The appropriateness of the design output in Task 2 showed a weak positive correlation with the concept links score of the mind map from Task 1, and a positive correlation with the mind map's image score. This finding suggested that when novice design students use mind maps for divergent thinking and engage in deeper and more detailed analyses of design topics, they can produce a more appropriate final output. In other words, when designers are able to present, consider, and articulate clearly the complex interrelations among design issues, they can be better prepared to conduct appropriateness analyses of their final design solutions in the early stages of the design process. Leeds et al. [66] mentioned that mind maps are better than lists in terms of concept associations. They also found that deeper responses, those further away from the root concept, tend to be more unique. Mind maps might be a better tool for idea associations because they provide a more concise overview of the idea hierarchy and knowledge network. At the same time, drawing detailed sketches when making mind maps can help novice design students integrate design elements more appropriately into the final design solution.

The originality of the design output in Task 2 was not correlated with the mind map's concept links score in Task 1. Thus, in the early stages of the design process, detailed analysis and understanding of design themes may not have a significant impact on creative thinking. The originality of the design output in Task 2 was positively correlated with the mind map's image score in Task 1. Therefore, if designers draw detailed sketches while making a mind map, their final design plan will more likely be original. The participants who used text and images in their mind maps scored higher in terms of originality for their design output. These results are consistent with the previous findings. According to Mento et al. [65], when building mind maps, it is helpful to use some artistic elements (icons or symbols). Wang et al. [57] showed that the structure of mind maps is open and organized, allowing individuals to organize a variety of information and generate more new ideas. With abundant colors, images, keywords or short sentences, such a map can facilitate thinking, memorizing, analyzing, and can trigger inspiration and enhance creativity among young children.

In addition, neither the appropriateness nor originality of the participants' design output in Task 2 correlated with their mind map's relationships scores in Task 1. A possible explanation would be that the participants were not required to use non-hierarchical mind maps. Only $31.4 \%$ of the participants' mind maps showed the usage of relationships, which resulted in low amounts of data, leading to low correlation. Malycha and Maier [31] mentioned that in the use of mind map, enhancing the density of information and increasing the interaction between complex tasks can promote the potential of mind map. Further 
experimental investigation on the role of relationships in mind maps need to be conducted in follow-up studies.

\subsection{Suggestions for Graphic Design Education}

This study offers some implications for design education and practice. The experimental results showed that mind mapping plays an important role in promoting creativity during the design phase. In the context of graphic design education, teachers should encourage novice designers to increase the number of concept links and of links per level in their mind maps when developing creative ideas. Teachers should also encourage students to construct in-depth ideas and develop them in a stepwise manner [66]. Meanwhile, students are encouraged to create graphics-based mind maps and use a variety of colours in the process rather than only words for associative thinking [49,80,81]. Kokotovich [16] showed that relationships in mind maps play an important role when analysing design problems because they allow designers to describe important and detailed interrelations between design problems in a dynamic and evolving manner that can further enhance and represent the designer's understanding of dynamically related issues in a given problem. They can also complement the understanding of various interrelations and can improve the quality of creative output. Therefore, it is recommended that novice designers add relationships to their mind maps to further enhance their understanding and analysis of any design problem and its accompanying issues. The study was conducted only on individuals. Studies have noted the importance of using mind maps in teams to communicate and create output collaboratively [49]. Zheng et al. [82] also found that the combination of a collaborative mind mapping strategy and a flipped classroom significantly improved students' learning achievement and self-efficacy. Therefore, subsequent studies can be conducted on the influence of mind mapping on team collaboration.

\section{Conclusions}

The results suggested that mind maps can promote sustainable creativity among graphic design students. How well a novice designer creates their mind map in the preconception design phase can affect the creativeness of their final design output. The design output's appropriateness is positively correlated with the mind map's concept links and image scores. The design output's originality is likewise positively correlated with the mind map's image score.

This study has some limitations that leave room for future studies. One is that we did not observe and record the entire design process. In future, we intend to conduct further investigations with a larger sample size in a real-life context. We also intend to conduct statistical analyses on the sketching process and the diversity and number of sketches, to contribute to a deeper understanding of the creative thinking process. Another limitation was that this study only used mind maps in the early stages of idea development in the design process. The mechanism of introducing mind maps in other stages of the design process was not clarified. Furthermore, it would be interesting to study how mind mapping may influence creativity in the large term, although the long-term creativity projects are usually complicated to carry out.

Author Contributions: Conceptualization, methodology, supervision, writing-original draft preparation, Y.D.; writing - reviewing and editing, S.Z.; data curation and writing-review and editing, W.L. All authors have read and agreed to the published version of the manuscript.

Funding: This research was funded by the National Natural Science Foundation of China (61902354).

Institutional Review Board Statement: Not applicable.

Informed Consent Statement: Not applicable.

Data Availability Statement: Not applicable.

Acknowledgments: In particular, we would like to thank all the design students of Zhejiang University of Technology who participated in this research. 
Conflicts of Interest: The authors declare that they have no known competing financial interests or personal relationships that could have appeared to influence the work reported in this paper.

\section{References}

1. Brem, A.; Puente-Díaz, R. Creativity, Innovation, Sustainability: A Conceptual Model for Future Research Efforts. Sustainability 2020, 12, 3139. [CrossRef]

2. Sternberg, R.J.; Lubart, T.I. The concept of creativity: Prospects and paradigms. In Handbook of Creativity; Cambridge University Press: Cambridge, UK, 1999; Volume 1-15.

3. Woodman, R.W.; Sawyer, J.E.; Griffin, R.W. Toward a theory of organizational creativity. Acad. Manag. Rev. 1993, 18, $293-321$. [CrossRef]

4. Zhang, Q.; Sun, S.; Zheng, X.; Liu, W. The role of cynicism and personal traits in the organizational political climate and sustainable creativity. Sustainability 2019, 11, 257. [CrossRef]

5. Beheshtifar, M.; Kamani-Fard, F.B. Organizational Creativity: A Substantial Factor to Growth. Int. J. Acad. Res. Bus. Soc. Sci. 2013, 3, 98-104.

6. Lemmetty, S.; Glăveanu, V.P.; Collin, K.; Forsman, P. (Un)Sustainable Creativity? Different Manager-Employee Perspectives in the Finnish Technology Sector. Sustainability 2020, 12, 3605.

7. Loewenberger, P. The role of HRD in stimulating, supporting and sustaining creativity and innovation. Hum. Resour. Dev. Rev. 2013, 12, 422-455. [CrossRef]

8. Ortiz, A.H.; López-Martínez, O.; Berná, F.J.C. Creative Talent and Personality: A Primary Education Study. Sustainability 2020, $12,4203$.

9. Marques, P.C. Building sustainable creativity: A conceptual framework. Eur. J. Sustain. Dev. 2016, 5, 433-439.

10. Carbonell-Carrera, C.; Saorin, J.L.; Melian-Diaz, D.; Torre-Cantero, J. Enhancing Creative Thinking in STEM with 3D CAD Modelling. Sustainability 2019, 11, 6036.

11. Ben-Eliyahu, A. Sustainable Learning in Education. Sustainability 2021, 13, 4250. [CrossRef]

12. Alhajri, S. Developing a Pedagogical Model to Enhance and Assess Creativity in Omani Graphic Design Education. Ph.D. Thesis, Philosophy of Loughborough University, Loughborough, UK, 2013.

13. Alhajri, S.A. Investigating Creativity in Graphic Design Education from Psychological Perspectives. Int. J. Arts Manag. 2017, 6, 69-89. [CrossRef]

14. Sandri, O.J. Exploring the role and value of creativity in education for sustainability. Environ. Educ. Res. 2013, 19, 765-778. [CrossRef]

15. Day, B.A. A generation of creativity. Appl. Environ. Educ. Commun. 2006, 5, 229-230. [CrossRef]

16. Kokotovich, V. Problem analysis and thinking tools: An empirical study of non-hierarchical mind mapping. Des. Stud. 2008, 29, 49-69. [CrossRef]

17. Barbour, S.C. A Study of Teaching Methods to Enhance Creativity and Critical Thinking in Graphic Design. Master's Thesis, Master of Fine Arts of Iowa State University, Ames, IA, USA, 2016.

18. Frascara, J. Graphic design: Fine Art or Social Science? Des. Issues 1988, 5, 18-29. [CrossRef]

19. Swanson, G. Graphic Design Education as a Liberal Art: Design and Knowledge in the University and the "Real World". Des. Issues 1994, 10, 53-63. [CrossRef]

20. Heller, S. The Education of a Graphic Designer; All worth Press: New York, NY, USA, 2005.

21. Ellmers, G. Reflection and Graphic Design Pedagogy: Developing a Reflective Framework to Enhance Learning in a Graphic Design Tertiary Environment. In ACUADS Conference, Thinking the Future: Art, Design and Creativity; Faculty of Art \& Design, Monash University: Melbourne, Australia, 2006; pp. 27-29.

22. Williams, R. The Long Revolution; Broadview Press: London, UK, 1961.

23. Buchanan, R. Design as a New Liberal Art. In Paper: The 1990 Conference on Design Education; Education Committee of the Industrial Designers Society of America: Pasadena, CA, USA, 1990.

24. Cheow, Y. Do Computers Undermine the Creative Process? Ph.D. Thesis, Nanyang Technological University, Singapore, 2010.

25. Runco, M.A. Commentary: Divergent thinking is not synonymous with creativity. Psychol. Aesthet. Creat. Arts 2008, 2, 93-96. [CrossRef]

26. Oxman, R. Think-maps: Teaching design thinking in design education. Des. Stud. 2004, 25, 63-91. [CrossRef]

27. Peng, L. Research on Thinking Process Model of Technological Innovation in Product Design. In Proceedings of the 2019 International Conferenceon Management, Lyon, France, 2 August 2019.

28. Malycha, C.P.; Maier, G.W. Enhancing creativity on different complexity levels by eliciting mental models. Psychol. Aesthet. Creat. Arts 2017, 11, 187-201. [CrossRef]

29. Chen, T.J.; Krishnamurthy, V.R. Investigating a Mixed-Initiative Work flow for Digital Mind-Mapping. J. Mech. Des. 2020, 142, 1-40. [CrossRef]

30. Camburn, B.; Arlitt, R.D.; Anderson, D.; Sanaei, R.; Raviselam, S.; Jensen, D.; Wood, K.L. Computer-aided mind map generation via crowdsourcing and machine learning. Res. Eng. Des. 2020, 31, 383-409. [CrossRef]

31. Malycha, C.P.; Maier, G.W. The random-map technique: Enhancing mind-mapping with a conceptual combination technique to foster creative potential. Creat. Res. J. 2017, 29, 114-124. [CrossRef] 
32. Dai, Z.; Wang, M.; Liu, S.; Tang, L. Design and the technology acceptance model analysis of instructional mapping. Comput. Appl. Eng. Educ. 2020, 28, 892-907. [CrossRef]

33. Davies, M. Concept mapping, mind mapping and argument mapping: What are the differences and do they matter? High. Educ. 2011, 62, 279-301. [CrossRef]

34. Martin, D. The cooperative use of material resources and contextual features in graphic design work. Des. Stud. 2012, 33, 589-610. [CrossRef]

35. Georgiev, G.V.; Nagai, Y.; Taura, T. Method of Creative Graphic Design Focusing on Multiple Meanings A systematic approach to meanings of symbols (TECHNICALSESSIONCONTENT). J. Design Stud. 2006, 53, 16-17.

36. Schiffman, C. Ethnovisual and Sociovisual Elements of Design: Visual Dialect as a Basis for Creativity in Public Service Graphic Design. J. Vis. Lit. 1994, 14, 23-39. [CrossRef]

37. Laing, S.; Masoodian, M. A study of the influence of visual imagery on graphic design ideation. Des. Stud. 2016, 45, 187-209. [CrossRef]

38. Walker, S. Research in Graphic Design. Des. J. 2017, 20, 549-559. [CrossRef]

39. Bennett, A. Design Studies: Theory and Research in Graphic Design; Princeton Architectural Press: New York, NY, USA, 2006.

40. Ambrose, G.; Harris, P. The Fundamentals of Graphic Design; AVA Publishing: Lausanne, Switzerland, 2009.

41. Givechi, R.; Groulx, I.; Woollard, M. Impact: Inspiring Graphic Design through Human Behaviors. In Design Studies-Theory and Research in Graphic Design, a Reader; Bennett, A., Ed.; Princeton Architectural Press: Princeton, NJ, USA, 2006 ; pp. 306-310.

42. Tomes, A.; Oates, C.; Armstrong, P. Talking Design: Negotiating the Verbal-Visual Translation. Des. Stud. 1998, 19, 127-142. [CrossRef]

43. Meggs, P.B.; Purvis, A. Meggs' History of Graphic Design; Wiley: Hoboken, NJ, USA, 2016.

44. Kansrirat, T.; Kiattikomol, P. Essential skills of training ideas generation in graphic design for non-graphic designers in Thailand. Glob. J. Eng. Educ. 2016, 18, 129-135.

45. Howard, T.J.; Culley, S.J.; Dekoninck, E. Describing the creative design process by the integration of engineering design and cognitive psychology literature. Des. Stud. 2008, 29, 160-180. [CrossRef]

46. Lin, R.T. Transforming Taiwan aboriginal cultural features into modern product design: A case study of across-cultural product design model. Int. J. Des. 2007, 1, 47-55.

47. Luo, S.J.; Dong, Y.N. Role of cultural inspiration with different types in cultural product design activities. Int. J. Technol. Des. Educ. 2017, 27, 499-515.

48. Zampetakis, L.A.; Tsironis, L.; Moustakis, V.S. Creativity development in engineering education: The case of mind mapping. J. Manag. Dev. 2007, 26, 370-380. [CrossRef]

49. Lin, C.C.; Shih, D.H. Mind Mapping: A Creative Development in Industrial Engineering Education. In Proceedings of the 2009 5th International Conference on Wireless Communications, Networking and Mobile Computing, Beijing, China, 2426 September 2009.

50. Gargouri, C.; Naatus, M.K. An Experiment in Mind-Mapping and Argument-Mapping: Tools for Assessing Outcomes in the Business Curriculum. e-J. Bus. Educ. Scholarsh. Teach. 2017, 11, 39-78.

51. Vijayakumari, K.; Kavithamole, M.G. Mind Mapping a tool for Mathematical Creativity. Guru J. Behav. Soc. Sci. 2014, 2, $242-246$.

52. Mandal, H.K. Brainstorming Approach and Mind Mapping in Synergy Creating Activity. Glob. J. Financ. Manag. 2014, 6, 333-338.

53. Utami, D.; Subali, B. The Effectiveness of 5E Learning Cycle Accompanied by Mind Mapping on Creative Thinking. In Proceeding of the 2nd International Conference Education Culture and Technology (ICONECT 2019), Kudus, Indonesia, 20-21 August 2019.

54. Burgess-Allen, J.; Owen-Smith, V. Using mind mapping techniques for rapid qualitative data analysis in public participation processes. Health Expect. 2010, 13, 406-415. [CrossRef]

55. Luz, T.D.; Loup-Escande, E.; Christofol, H.; Richir, S. The Collaborative Product Design and Help to Decision Making: Interactive Mind-Mapping. In Global Product Development. In Proceedings of the 20th CIRP Design Conference, Ecole Centrale de, Nantes, Nantes, France, 19-21 April 2010; Springer: Berlin/Heidelberg, Germany, 2011; pp. 237-244.

56. Hsieh, M.H.; Chang, C.L. Product Awareness Between Consumers and Designers-A Family Dining Table Design as Example. In International Conference on Human Interface $\mathcal{E}$ the Management of Information; Springer International Publishing: Cham, Switzerland, 2016.

57. Wang, W.C.; Lee, C.C.; Chu, Y.C. A Brief Review on Developing Creative Thinking in Young Children by Mind Mapping. Int. Bus. Res. 2010, 3, 233-238. [CrossRef]

58. Pereira, T.M.; Arez, A.; Vieira, N. Cartographies of the creative process: Use of mind mapping in contexts of artistic education. In Proceedings of the 2017 International Symposiumon Computers in Education (SIIE), Lisbon, Portugal, 9-11 November 2017.

59. Anderson, J.V. Mind mapping: A tool for creative thinking. Bus. Horiz. 1993, 36, 41-46. [CrossRef]

60. Garlough, D. Mind mapping for a creative breakthrough. $R D H$ 2013, 33, 22-96.

61. Crowe, M.; Sheppard, L. Mind mapping research methods. Qual. Quant. 2012, 46, 1493-1504. [CrossRef]

62. Biktimirov, E.N.; Nilson, L.B. Show them the money: Using mind mapping in the introductory finance course. J. Financ. Educ. 2006, 32, 72-86.

63. Nettleship, J. Active learning in economics: Mind maps and wall charts. Economics 1992, 25, 69-71.

64. Eriksson, L.T.; Hauer, A.M. Mind map marketing: A creative approach in developing marketing skills. J. Mark. Educ. 2004, 26, 174-187. [CrossRef] 
65. Mento, A.; Martinelli, P.; Jones, R.M. Mind mapping in executive education: Applications and outcomes. J. Manag. Dev. 1999, 18, 390-416. [CrossRef]

66. Leeds, A.J.; Kudrowitz, B.; Kwon, J. Mapping associations: Exploring divergent thinking through mind mapping. Int. J. Des. Creat. Innov. 2019, 7, 16-29. [CrossRef]

67. Thamrin, D. Experimental Design in the Cultural Space Interior Design Studio Linear Programmatic versus Holistic Mindmapping Approach. In Proceedings of the DRS 2012 Bangkok, Chulalongkorn University Bangkok, Bangkok, Thailand, 15 July 2011.

68. Chen, J.X. The using of mind map in concept design. In Proceedings of the 2008 IEEE 9th International Conference on ComputerAided Industrial Design \& Conceptual Design, Location of Conference, Beijing, China, 22-25 November 2008; IEEE: Beijing, China, 2008.

69. Zubaidah, S.; Fuad, N.M.; Mahanal, S.; Suarsini, E. Improving Creative Thinking Skills of Students through Differentiated Science Inquiry Integrated with Mind Map. J. Turk. Sci. Educ. 2017, 14, 78-91.

70. Polat, Ö.; Aydn, E. The effect of mind mapping on young children's critical thinking skills. Think. Ski. Creat. 2020, 38, 1-14. [CrossRef]

71. Widiana, I.W.; Jampel, I.N. Improving Students' Creative Thinking and Achievement through the Implementation of Multiple Intelligence Approach with Mind Mapping. Int. J. Eval. Res. Educ. 2016, 5, 246-254. [CrossRef]

72. Evrekli, E.; İnel, D.; Balım, A.G. Development of a scoring system to assess mindmaps. Procedia Soc. Behav. Sci. 2010, 2, 2330-2334. [CrossRef]

73. Amabile, T. The Social Psychology of Creativity; Springer: New York, NY, USA, 1983.

74. Shalley, C.E.; Gilson, L.L. What leaders need to know: Are view of social and contextual factors that can foster or hinder creativity. Leadersh. Q. 2004, 15, 33-53. [CrossRef]

75. Kerne, A.; Koh, E.; Smith, S.M.; Choi, H.; Graeber, R.; Webb, A. Promoting emergence in information discovery by representing collections with composition. Proc. ACM Creat. Cogn. 2007, 117-126. [CrossRef]

76. Shah, J.J.; Vargas-Hernandez, N.; Smith, S.M. Metrics for measuring ideation effectiveness. Des. Stud. 2003, 24, 111-134. [CrossRef]

77. Cheng, P.Y.; Mugge, R.; Schoormans, J.P.L. A new strategy to reduce design fixation: Presenting partial photo graphs to designers. Des. Stud. 2014, 35, 374-391. [CrossRef]

78. Goldschmidt, G.; Smolkov, M. Variances in the impact of visual stimuli on design problem solving performance. Des. Stud. 2006, 27, 549-569. [CrossRef]

79. Goldschmidt, G.; Sever, A.L. Inspiring design ideas with texts. Des. Stud. 2011, 32, 139-155. [CrossRef]

80. Buzan, T.; Buzan, B. The Mind Map Book: How to Use Radiant Thinking to Maximize Your Brain's Untapped Potential; Plume: New York, NY, USA, 1996.

81. North, V. Mind maps chart the way to business efficiency. Educ. Train. 1998, 40, 173-174.

82. Zheng, X.; Johnson, T.E.; Zhou, C. A pilot study examining the impact of collaborative mind mapping strategy in a flipped classroom: Learning achievement, self-efficacy, motivation, and students' acceptance. Educ. Technol. Res. Dev. 2020, 68, 3527-3545. [CrossRef] 